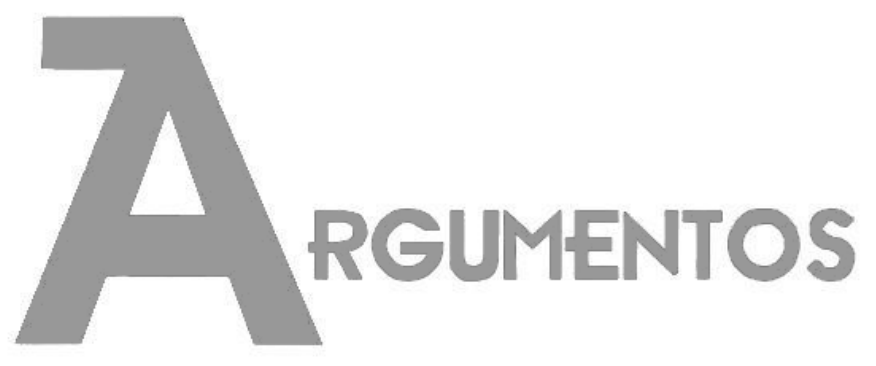

Vol. 18, n. 1, jan./jun. 2021 ISSN: 2527-2551 (online)

\title{
A Organização do Quadro Social como instrumento da Educação Cooperativista
}

Diego Neves de Sousa ${ }^{1}$

Palloma Rosa Ferreira²

Recebido em: 10/10/2019

Aprovado em: 23/07/2020

\begin{abstract}
Resumo: A Organização do Quadro Social (OQS) emerge como prática educativa reconhecida pelos interlocutores das cooperativas e por órgãos representativos do cooperativismo por ser primordial no desenvolvimento de trabalho educativo de capacitação e para o avanço da participação dos membros associados nas instâncias de decisão. Neste intento, o objetivo deste artigo é analisar as potencialidades da Organização do Quadro Social como instrumento da educação cooperativista. A pesquisa é de caráter quali-quantitativa. Obteve-se a participação de 51cooperativas agrárias do Estado de Minas Gerais que responderam ao questionário. Entre os resultados, postula-se que as cooperativas agrárias contam com o instrumento de Organização do Quadro Social para viabilizar a educação cooperativista, no entanto nem todas utilizam deste recurso para informar, comunicar e capacitar os associados e seus públicos de interesse.
\end{abstract}

Palavras-chave: Cooperativas Agrárias, Capacitação, Comitê educativo, ensino aprendizagem.

\section{La Organización del Cuadro Social como instrumento de la educación cooperativista}

Resumen: La Organización del Cuadro Social (OQS) surge como una práctica educativa reconocida por los interlocutores de las cooperativas y por los organismos representativos de la cooperativa porque es esencial en el desarrollo del trabajo de capacitación educativa y para el avance de la participación de los miembros asociados en los órganos de toma de decisiones. En este sentido, el objetivo de este artículo es analizar el potencial de la Organización de Membresía como instrumento de educación cooperativa. La investigación es de naturaleza cualitativa y cuantitativa. 51 cooperativas agrarias del estado de Minas Gerais respondieron al cuestionario. Entre los resultados, se postula que las cooperativas agrarias tienen el instrumento

\footnotetext{
${ }^{1}$ Doutor em Desenvolvimento Rural, Universidade Federal do Rio Grande do Sul, Brasil. Analista da Embrapa Pesca e Aquicultura, Palmas, Brasil. E-mail: diego.sousa@embrapa.br. ORCID: http://orcid.org/0000-0003-3124-5150.

2 Doutoranda em Economia Doméstica (UFV), Viçosa, Brasil. E-mail: pallomarf@yahoo.com.br. ORCID: http://orcid.org/0000-0001-7523-4731.
} 
Artigos | A Organização do Quadro Social como instrumento da Educação Cooperativista (SOUSA, Diego Neves de; FERREIRA, Palloma Rosa)

de Organización del Cuadro Social para hacer factible la educación cooperativa, sin embargo, no todas usan este recurso para informar, comunicar y capacitar a los miembros y sus partes interesadas.

Palabras-clave: Cooperativas Agrario, Formación, Comité Educativo, enseñanza y aprendizaje.

\section{The Membership Organization as an instrument of cooperative education}

Abstract: The Organization of the Membership (OQS) emerges as an educational practice recognized by the interlocutors of the cooperatives and by representative bodies of the cooperativism for being essential in the development of educational training and for the advancement of the participation of associate members in decision-making bodies. In this regard, the objective of this article is to analyze the potential of the Membership Organization as an instrument of cooperative education. The research is of a qualitative and quantitative nature. 51 agrarian cooperatives from the State of Minas Gerais responded to the questionnaire. Among the results, it is postulated that agrarian cooperatives have the Organization of the Membership instrument to make cooperative education feasible, however not all use this resource to inform, communicate and train members and their stakeholders.

Keywords: Agrarian Cooperatives, Training, Educational Committee, teaching and learning.

\section{Introdução}

A educação cooperativista é um dos pilares em que se assenta o desenvolvimento das organizações cooperativas. Isso é reconhecido desde as origens do movimento cooperativo e continua sendo reiteradamente afirmado por integrantes das cooperativas contemporâneas, não só quando perguntados especificamente sobre isso, mas também quando chamados a elencar os pontos críticos que asseguram o êxito destas organizações - ou, pela negativa, quando enumeram entre os principais problemas, as questões vinculadas à deficiente educação cooperativista. Este problema aparece recorrentemente na maioria das experiências cooperativas brasileiras (FERREIRA; AMODEO; SOUSA, 2013). Uma das possíveis explicações é que os representantes das cooperativas têm a consciência sobre a importância de se realizar trabalhos de educação cooperativista, mas têm dificuldades para a execução (FERREIRA; SOUSA; AMODEO, 2018).

Neste intento, a Organização do Quadro Social (OQS) emerge como um instrumento utilizado para desenvolver a educação cooperativa em que a prática educativa é reconhecida pelos interlocutores das cooperativas e por órgãos de representação do cooperativismo por ser primordial no desenvolvimento de trabalho educativo de capacitação e formação dos associados. Isto está atrelado a ideia de que proporcionalmente está ligada ao avanço da participação dos membros associados em 
Artigos | A Organização do Quadro Social como instrumento da Educação Cooperativista (SOUSA, Diego Neves de; FERREIRA, Palloma Rosa)

instâncias decisivas na organização. É uma forma de organizar a gestão social muito utilizada nas cooperativas agrárias. Se bem conduzida, a OQS pode viabilizar importantes espaços de capacitação e participação do quadro social, aumentando de maneira considerável o envolvimento direto de diferentes grupos de produtores rurais associados no processo de tomada de decisão e controle da gestão empresarial de cooperativas.

Para Valadares (1995), a OQS está pautada por diversas práticas educativas que têm como proposta a formação de uma nova instância de poder nas cooperativas, além das usualmente percebidas neste tipo de organização. Um dos resultados da institucionalização da OQS é a formação de Comitês Educativos que oportuniza a existência de diferentes formas organizacionais e particularidades de seu funcionamento com o intuito de "estruturar um espaço de poder na cooperativa, viabilizando a participação democrática do maior número de associados na gestão do empreendimento cooperativo" (VALADARES, 1995, p.47).

Isto porque a institucionalização da prática de OQS nas cooperativas significa uma instância a mais de participação, porém de caráter menos formal que as assembleias, no ambiente deste tipo de organização coletiva. A OQS viabiliza a ampliação do exercício do poder na cooperativa, conduzindo a novas formas de controle democrático e de participação dos associados na vida de suas cooperativas. Geralmente, organizam-se comissões locais em diferentes lugares da área de influência da cooperativa, constituídas por associados, que ser reúnem periodicamente para obter informações de sua organização e dos produtos, discutir questões do seu interesse vinculadas à cooperativa, receber capacitação em diversos aspectos - incluídas questões técnico-produtivas - etc. É passível de mencionar que, por meio da instrumentalização da OQS nas cooperativas agrárias, três conteúdos são diretamente contemplados: a gestão social, a gestão empresarial e a assistência técnica (FERREIRA; AMODEO; SOUSA, 2013).

A educação cooperativista referente ao ramo agropecuário dispensa atenção de modo especial as capacitações vinculadas com assistência técnica direcionada aos produtores associados, visando a influenciar nos processos produtivos das propriedades dos cooperados através de práticas educativas. Assim, neste caso, as empresas prestadoras do serviço de extensão rural contribuem significativamente para o 
Artigos | A Organização do Quadro Social como instrumento da Educação Cooperativista (SOUSA, Diego Neves de; FERREIRA, Palloma Rosa)

estabelecimento de atividades de educação cooperativista junto as organizações cooperativas agrárias (FERREIRA; SOUSA; COSTA, 2018).

Neste contexto, a educação e a informação permanentes dos associados adquirem um lugar de destaque na gestão social das cooperativas (VALADARES, 2005). Por educação cooperativista entende-se como um processo permanente e contínuo de aprendizagem que contempla harmoniosamente a gestão social e empresarial das cooperativas e as demandas específicas de formação dos públicos envolvidos a elas como forma de melhorar a participação nas instâncias decisivas, mas desde que atenda às particularidades de cada ramo cooperativista (FERREIRA; SOUSA, 2019).

Cita-se o exemplo do complexo de cooperativas de Mondragón na Espanha. Em 2005, reorganizou seus processos de inovação e de desenvolvimento baseado em uma estratégia de educação cooperativista instrumentalizada em três formatos: cursos de oito horas, cursos de formação de dois a três dias para órgãos sociais e diretivos e cursos de Pós-graduação com duração de 250 horas. A ideia principal foi promover projetos educativos voltados para a transformação social como é o caso da busca por novos modos de produção e consumo consciente, valorização do indivíduo e da sociedade, apoiar agricultura de base agroecológica e novas formas de gerir a propriedade rural. Dessa forma, a proposição de ações de educação cooperativista vem se constituindo por meio de propostas intervencionistas que ofereçam significado para as cooperativas (ALCÂNTARA; SAMPAIO; ZABALA, 2018; ALCANTARA; SAMPAIO; URIARTE, 2018).

É importante mencionar, ainda, que ao se pensar sobre as ações estratégicas de educação cooperativista a serem implementadas em uma cooperativa é fundamental que atenda aos próprios imperativos de capacitação intrínsecos aos seus princípios e ao seu ramo (ou tipologia) numa perspectiva de construir um projeto político-pedagógico capaz de dar suporte a essas demandas (FERREIRA; SOUSA, 2018). Neste contexto, a OQS é um dos principais instrumentos para colocar em prática a educação cooperativista e, assim, impulsionar o desenvolvimento das cooperativas e das comunidades em que estão inseridas.

Assim, se, por um lado, a implementação dessa prática educativa pode significar para os pequenos produtores, maiores possibilidades de acesso a bens e serviços prestados pelas cooperativas; por outro lado, para os grandes e consolidados produtores, a participação pode assumir ares de ameaça, isso devido à introdução de 
Artigos | A Organização do Quadro Social como instrumento da Educação Cooperativista (SOUSA, Diego Neves de; FERREIRA, Palloma Rosa)

novos atores sociais que passam a participar mais ativamente do processo decisório da cooperativa. Desta forma, esta situação "traz implicações políticas significativas na conformação do conflito entre grupos dominantes e dominados em espaços regionais da área de ação da cooperativa" (VALADARES, 1996, p.11). Por isso, essa importante prática educativa pode ser comprometida pela ação de forças contrárias à sua real implementação. Isto não deveria acontecer, pois um dos princípios que regem este tipo de organização é a participação social dos seus membros associados.

Ainda segundo Valadares (1996), para dar vida aos trabalhos relacionados à Organização do Quadro Social, muitas cooperativas agrárias estão criando um Departamento próprio ou Comitê Educativo, que se encontra vinculado diretamente ao Conselho de Administração, responsável por assumir as atividades relativas ao desenvolvimento social e político dos associados, no intuito de prepará-los, por meio das atividades de capacitação, para que possam atuar como verdadeiros donos e usuários do empreendimento cooperativo.

O crescimento do número de associados das cooperativas agrárias tem provocado o distanciamento dos associados de suas cooperativas, impossibilitando, dessa forma, sua participação. Assim, muitas cooperativas têm buscado estabelecer, de maneira institucional, a formação de subgrupos em várias localidades pertencentes ao seu âmbito de atuação, objetivando melhorar as condições de participação dos associados, permitindo, deste modo, enfrentar em grupo os aspectos burocráticos da cooperativa, constituindo-se, nas palavras de Valadares (1996, p. 17), "em um canal através do qual os associados podem expressar suas necessidades, desejos e inquietudes, além de constituir um meio de comunicação e informação importante entre os dirigentes e as bases sociais".

Assim, uma das bases primordiais para o funcionamento da OQS é ter um processo de comunicação eficiente para dar suporte aos trabalhos de educação cooperativista. A ideia é que a comunicação possa ser vista como uma ferramenta de auxílio para as ações da gestão cooperativa, particularmente o de educação cooperativista para atingir seus objetivos com base em seus princípios (SOUSA et al., 2018). Portanto, é importante que "a educação cooperativista e a comunicação devam andar juntas, como práticas indissociáveis do processo da gestão cooperativa, visando maior competitividade destas organizações" (SOUSA et al, 2014, p.512). 
Artigos | A Organização do Quadro Social como instrumento da Educação Cooperativista (SOUSA, Diego Neves de; FERREIRA, Palloma Rosa)

Mais adiante continuaremos aprofundando outros aspectos da OQS. Neste contexto, o objetivo deste artigo é analisar as potencialidades da Organização do Quadro Social como instrumento da educação cooperativista. A pesquisa é de caráter quali-quantitativa. Nos procedimentos metodológicos foram enviados questionários as cooperativas agrárias do Estado de Minas Gerais, no qual obtivemos 51 respostas.

\section{Histórico e aspectos sobre a institucionalização da Organização do Quadro Social}

No Estado do Paraná, no ano de 1962, ocorreu a criação do primeiro comitê de extensão rural, na cidade União da Vitória-PR, com o objetivo de identificar e renovar os "líderes rurais nas comunidades para procurar soluções dos problemas por eles apontados" (SUDECOOP, 1994, p. 20). Observa-se, neste sentido, que a ideia de "comitê educativo" tem suas raízes históricas na própria extensão rural, devido à organização dos produtores rurais em comitês comunitários e municipais (SUDECOOP, 1994).

Contudo, a materialização do modelo de Comitê educativo no Brasil foi concretizada pelas mãos do Dr. Benjamim Hammerschimidt, seu idealizador, sendo que a primeira experiência foi realizada na Cooperativa Mista Bom Jesus Ltda., em Lapa-PR, contando com o apoio e a participação de vários técnicos da Associação de Crédito e Assistência Rural do Paraná (Acarpa). O sucesso da experiência fez com que outras cooperativas paranaenses também adotassem o modelo, sendo disseminado posteriormente para os demais Estados (SUDECOOP, 1994).

Este movimento ressoou de tal maneira em todo país que, em março de 1985, a própria Organização das Cooperativas Brasileiras (OCB) assume a direção dos trabalhos, com o intuito de elaborar um programa abrangente de educação cooperativista. Para tanto, define políticas, diretrizes e o primeiro plano quinzenal de atividades, objetivando, desta forma, a organização do quadro social em todas as cooperativas brasileiras (SUDECOOP, 1994).

Assim, com base nestas diretrizes elaboradas pela OCB, a Ocemg, em parceria com a Denaccop e Sudecoop, inicia em 1988 os trabalhos de implantação da prática de OQS nas cooperativas agropecuárias. De acordo com as entrevistas, a Ocemg, com o 
Artigos | A Organização do Quadro Social como instrumento da Educação Cooperativista (SOUSA, Diego Neves de; FERREIRA, Palloma Rosa)

objetivo de aprofundar este movimento, passou a incentivar os Encontros Estaduais de Comitês Educativos.

Este trabalho foi desenvolvido em uma média de doze cooperativas, dentre elas podem-se citar as das cidades de Divinópolis, Uberlândia, Araxá, Prata, Paracatu, Unaí e Patrocínio. Com estes incentivos, observou-se que, dentre as cooperativas que optaram por adotar esta prática, houve aquelas que deram sequência aos trabalhos, conduzindoos até os dias atuais. Outras, por determinadas debilidades que enfrentaram no empreendimento, principalmente problemas de ordem financeira, abandonaram esta prática, priorizando outras atividades em detrimento da educação cooperativista, devido aos custos embutidos neste processo.

Neste ponto é interessante esclarecer que para instrumentalizar, mas que também seja um processo de ensino aprendizagem, o trabalho de OQS é crucial que os associados façam parte de algum modelo de organização, que necessariamente vai ao encontro do atendimento das expectativas da cooperativa, o que significa dizer, dos seus coproprietários. Assim, além dos comitês educativos, podem-se destacar os núcleos de cooperados, colegiados, comissões, grupos específicos, formas mistas, comitê de ética, conselhos, comitês especializados ou grupos de associados, entre outros. Estes modelos apresentam bastante similaridade entre si, por isso o primordial de tais modelos é viabilizar o fluxo de informação entre cooperados e a diretoria, além de propiciar maior participação do corpo de associados na gestão da cooperativa.

Assim, segundo relatos dos entrevistados diretamente envolvidos neste trabalho, fomentado pela parceria anteriormente mencionada, as cooperativas ficavam responsáveis por escolher entre os seus funcionários um representante; ou, se preferissem, tinham a opção de contratar um agente de capacitação, no caso um técnico, que tivesse principalmente formação em cooperativismo. Esta pessoa recebia treinamento, ministrado por um técnico da Ocemg, que tinha a incumbência de ensinar a implantar o programa (OQS) e assessorar estes indivíduos, tanto no início do desenvolvimento dos trabalhos, como no decorrer do processo, de acordo com as demandas apresentadas. Depois de definida a área de atuação da cooperativa, cada comunidade escolhia democraticamente, na segunda ou terceira reunião, o Conselho de Representantes, composto por um coordenador e vice coordenador, representantes de cada uma das comunidades e um secretário e vice-secretário. Essa reunião ocorria 
Artigos | A Organização do Quadro Social como instrumento da Educação Cooperativista (SOUSA, Diego Neves de; FERREIRA, Palloma Rosa)

na própria comunidade por meio dos comitês educativos. Estes comitês funcionam como um órgão auxiliar consultivo da administração, porém sem poder de decisão, na verdade, em sua essência se constituía em um órgão de assessoria.

Deste modo, representantes das comunidades reuniam-se no Comitê Central localizado na cooperativa para socializar as informações do que estava acontecendo em cada comitê/núcleo das comunidades, para avaliar quais problemas e demandas das comunidades deveriam ser levados à diretoria. Os membros da diretoria então participam da reunião com os representantes dos Comitês, que apresentavam os principais pontos centrais anteriormente discutidos. Em contrapartida, a diretoria também repassava para os representantes os planos de trabalho, suas metas, informações a respeito da cooperativa. Com base nas respostas da diretoria às necessidades e problemas apontados, e dependendo da relevância das informações transmitidas, convocava-se uma reunião extraordinária na comunidade a fim de socializar com os cooperados o que fora discutido ou esperava-se a reunião ordinária com data pré-estabelecida.

É interessante ressaltar que normalmente as reuniões nas comunidades duravam por volta de duas horas, dependendo do contexto, sendo divididas em três etapas distintas. Uma primeira etapa de teor informativo (com duração aproximada de quinze minutos), cujos temas privilegiados tinham relação com algumas práticas habituais das atividades realizadas pelos produtores rurais em sua propriedade, questões práticas do dia-a-dia com o intuito de nivelar informações entre os produtores. À segunda parte da reunião, que era a principal, chamavam "educação cooperativista" e era nesta que ocorriam um levantamento e discussões sobre os problemas sentidos e vivenciados pelos cooperados daquela comunidade (em relação à cooperativa ou não). Esta segunda parte era realizada em mais ou menos uma hora. Por fim, a terceira parte (de quarenta minutos, no máximo) era composta de uma palestra técnica apoiada em algum assunto de interesse dos associados. Cabe ressaltar que os técnicos agentes em educação estavam presentes em grande parte destas reuniões (SUDECOOP, 1994).

Nota-se, deste modo, que o trabalho de OQS nas cooperativas promovido pela Sudecoop e Ocemg é até hoje utilizado com este formato pelas cooperativas, como suporte para o desenvolvimento deste tipo de processo educacional. Deve-se mencionar, no entanto, que a estrutura da OQS vai depender muito do ambiente 
Artigos | A Organização do Quadro Social como instrumento da Educação Cooperativista (SOUSA, Diego Neves de; FERREIRA, Palloma Rosa)

organizacional de cada cooperativa, sendo essencial que ela mesma crie as condições necessárias para que os associados desenvolvam os próprios instrumentos para atuar de forma organizada, de acordo com a realidade social na qual vivem.

No ano de 2007, a Ocemg/Sescoop-MG retomou esse trabalho em parceria com a UFV-DER e a Sucoop. Para tanto, estudantes do Curso de Gestão de Cooperativas realizaram esse trabalho de OQS sob a forma de estágio.

Conscientes de sua atuação como sócios de um empreendimento coletivo, os associados e seus familiares se envolvem e se comprometem mais com a gestão de suas cooperativas, auxiliando a administração no processo de tomada de decisões, que irá diagnosticar constantemente os anseios dos associados, tornando a gestão mais transparente e a cooperativa um instrumento real de resposta às necessidades de seus sócios (Retirado do site www.ocemg.org.br em março de 2017).

Este mecanismo de educação cooperativista, se conduzido de maneira satisfatória, permite intensificar a comunicação cooperados/diretoria e aumentar o grau de participação e de credibilidade dos associados no empreendimento, que, conscientes do seu papel, passam a ser importantes motores de desenvolvimento da cooperativa. Isto posto, acrescenta-se que

Organizar o quadro social é defini-lo e estruturá-lo de forma tal que se possa estabelecer um processo sistemático e permanente de comunicação entre este e a cooperativa. (...) o principal objetivo de organizar o quadro social é o de possibilitar a participação deste na dinâmica da cooperativa, levando-o a vivenciar o princípio cooperativista da gestão democrática (SUDECOOP, 1994, p. 20).

Neste sentido, a proposta de OQS está baseada em um trabalho educativo de capacitação e formação dos associados, que se traduz em um movimento de busca constante pela concretização da autogestão nos empreendimentos cooperativos por meio da intensificação da participação democrática de seus membros. Contudo, para instrumentalizar esse processo nas cooperativas, determinadas deficiências precisam ser extintas ou pelo menos minimizadas.

Valadares (1996) aponta que estas recorrentes deficiências estão relacionadas ao não comprometimento dos dirigentes cooperativistas no processo de OQS, aos 
Artigos | A Organização do Quadro Social como instrumento da Educação Cooperativista (SOUSA, Diego Neves de; FERREIRA, Palloma Rosa)

problemas concernentes às metodologias dos processos de educação e comunicação cooperativa e ainda ao despreparo dos técnicos que atuam nos projetos educacionais existentes, por muitas vezes não possuírem conhecimento suficientes sobre os aspectos peculiares que estão presentes nos empreendimentos cooperativos.

De igual modo, a OQS pode vir a mascarar as relações de poder na cooperativa, especialmente quando os incentivos para a participação política dos membros acontecem para reafirmar o poder de uma minoria, seja formalmente, através de um sistema de normas e acordos elaborados pela própria cooperativa, ou informalmente, contando com o consenso passivo e/ou a interação meramente formal dos membros. Nestes termos, na prática da participação do comitê educativo, precisam ser criados mecanismos coerentes para equilibrar a tensão existente entre a democracia formal $e$ real. A primeira é realizada por meio de órgãos e pela elaboração de regras, criadas para auxiliar no processo de tomadas de decisões nos empreendimentos cooperativos, como os regimentos e estatuto; já a segunda refere-se à rede de distribuição do poder, composta pelos dirigentes, associados, quadro funcional e por grupos que possuem algum tipo de influência sobre a cooperativa. Neste contexto, os trabalhos devem ser direcionados no sentido de concretizar a efetivação da democracia real, com o consequente cumprimento da democracia formal (VALADARES, 1996).

Assim, as cooperativas agrárias brasileiras contam com um recurso organizacional destinado a viabilizar a educação cooperativista, localmente focado e organizacionalmente estruturado, de forma a permitir simultaneamente a informação, a comunicação e capacitação dos associados, embora seja utilizado somente por algumas delas. Como são requeridos gastos organizativos e pessoal especializado, assim como dedicação de tempo dos dirigentes para implementar a OQS, esses recursos podem ser visualizados equivocadamente como custos, e não como investimentos para melhorar a gestão cooperativa (MACEDO, SOUSA e AMODEO, 2013, 2014).

Como mencionado anteriormente, a insuficiente participação do corpo de associados nas organizações cooperativas ainda é um fator preocupante para o sistema cooperativista como um todo.

\section{Resultados e discussão}


Artigos | A Organização do Quadro Social como instrumento da Educação Cooperativista (SOUSA, Diego Neves de; FERREIRA, Palloma Rosa)

Neste contexto, tornou-se determinante identificar se as cooperativas agrárias têm realizado a prática de OQS, pela importância que apresenta como ferramenta de participação e educação cooperativista, especialmente porque esta prática foi e ainda é desenvolvida de modo especial pelo ramo agropecuário. Assim, dentre as 51 cooperativas participantes da pesquisa, pouco mais da metade, $54 \%$, responderam não realizar ações de OQS, enquanto $46 \%$ afirmaram realizar este trabalho.

Dentre as que responderam positivamente, o desenvolvimento da OQS é feito prioritariamente por meio de comitês educativos, grupos de produtores e núcleos locais. Em menor medida recorre-se a comissões por produtos e serviços e a comissões regionais e de representantes. A forma como as cooperativas pesquisadas desenvolvem a OQS e sua frequência são apresentados na Figura 1.

Figura 1: Meios de realização da OQS

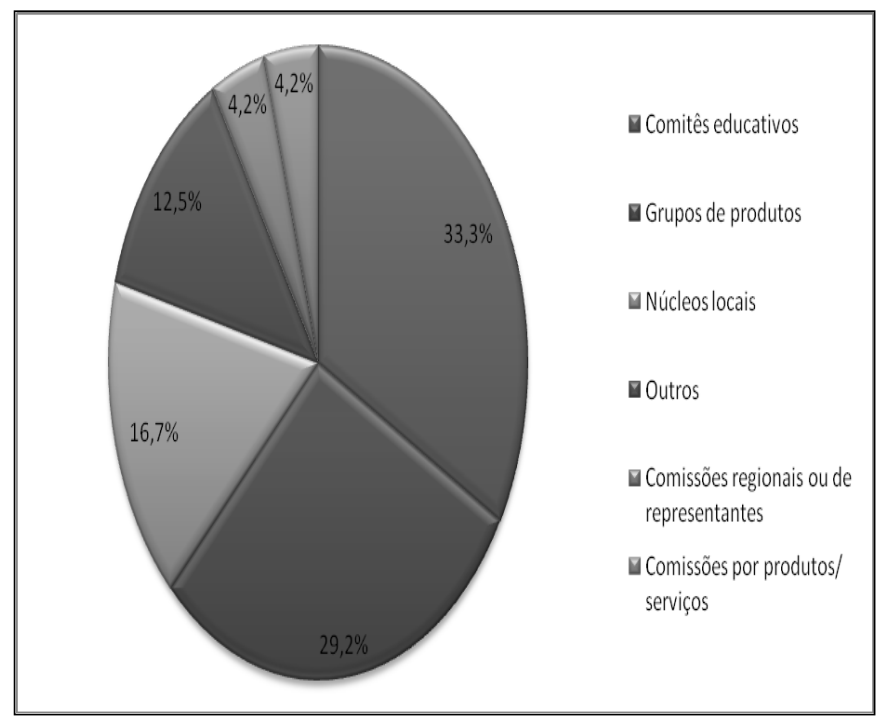

Fonte: Elaboração própria dos autores.

Apesar de a OQS ser uma importante instância de participação e controle democrático das cooperativas, e que grande parte das experiências brasileiras de OQS identificadas estejam relacionadas com o cooperativismo agrário, os dados indicam que esta prática ainda não é predominante nas organizações pesquisadas.

Dois problemas derivam da inexistência desta prática. De um lado, os pequenos produtores associados têm menores possibilidades de acesso ampliado aos bens e serviços prestados pelas cooperativas e à participação na gestão da mesma. De outro, 
Artigos | A Organização do Quadro Social como instrumento da Educação Cooperativista (SOUSA, Diego Neves de; FERREIRA, Palloma Rosa)

isto pode representar para os grandes produtores a manutenção de uma situação privilegiada, já que a eventual introdução de novos atores, antes afastados do poder, poderia intervir de maneira mais sistemática nos processos decisórios das cooperativas e mudar seus rumos (VALADARES, 1996; SOUSA et al., 2014, 2015).

Também, procurou-se identificar a percepção que os interlocutores das cooperativas possuem sobre a importância de se planejar ações de educação cooperativista para as suas organizações e qual a sua contribuição para o ambiente destes empreendimentos coletivos. Quando indagados sobre o papel que cumpre a educação cooperativista para suas organizações, os respondentes que afirmaram realizar educação cooperativista foram enfáticos em apontar que, de modo especial, está relacionada ao aprimoramento do conhecimento sobre a cultura cooperativista e seus princípios. Afirmam também que por meio desta educação cooperativa se torna possível identificar os verdadeiros preceitos do cooperativismo. A título de exemplo, podem-se citar as palavras de um técnico em educação cooperativista, respondente de um dos questionários, que afirma que "o conhecimento é a chave que abre as portas das oportunidades e estas levam o homem a encontrar os valores vitais de sua sobrevivência. No sistema cooperativista a educação tem esta condição".

Neste sentido, a proposta de OQS está baseada em um trabalho educativo de capacitação e formação dos associados, que se traduz em um movimento de busca constante pela concretização da autogestão nos empreendimentos cooperativos por meio da intensificação da participação democrática de seus membros. Contudo, para instrumentalizar esse processo nas cooperativas, determinadas deficiências precisam ser extintas ou pelo menos minimizadas na gestão cooperativa.

Valadares (1996) e Sousa et al. (2013) apontam que estas recorrentes deficiências estão relacionadas ao não comprometimento dos dirigentes cooperativistas no processo de OQS, aos problemas concernentes às metodologias dos processos de educação e comunicação cooperativa e ainda ao despreparo dos técnicos que atuam nos projetos educacionais existentes, por muitas vezes não possuírem conhecimento suficientes sobre os aspectos peculiares que estão presentes nos empreendimentos cooperativos e da própria educação cooperativista que pode inibir o processo de intervenção sociotécnica. 
Artigos | A Organização do Quadro Social como instrumento da Educação Cooperativista (SOUSA, Diego Neves de; FERREIRA, Palloma Rosa)

De igual modo, a OQS pode vir a mascarar as relações de poder na cooperativa, especialmente quando os incentivos para a participação política dos membros acontecem para reafirmar o poder de uma minoria, seja formalmente, através de um sistema de normas e acordos elaborados pela própria cooperativa, ou informalmente, contando com o consenso passivo e/ou a interação meramente formal dos membros. Nestes termos, na prática da participação do comitê educativo, precisam ser criados mecanismos coerentes para equilibrar a tensão existente entre a democracia formal $e$ real. A primeira é realizada por meio de órgãos e pela elaboração de regras, criadas para auxiliar no processo de tomadas de decisões nos empreendimentos cooperativos, como os regimentos e estatuto; já a segunda refere-se à rede de distribuição do poder, composta pelos dirigentes, associados, quadro funcional e por grupos que possuem algum tipo de influência sobre a cooperativa. Neste contexto, os trabalhos devem ser direcionados no sentido de concretizar a efetivação da democracia real, com o consequente cumprimento da democracia formal (VALADARES, 1996).

\section{Conclusão}

Conclui-se que as cooperativas agrárias pesquisadas contam com um recurso organizacional destinado a viabilizar a educação cooperativista, no qual é considerado a Organização do Quadro Social, localmente focado e organizacionalmente estruturado, de forma a permitir simultaneamente a informação, a comunicação e capacitação dos associados (e seus públicos de interesse), embora seja utilizado somente por algumas delas. Como são requeridos gastos organizativos e pessoal especializado, assim como dedicação de tempo dos dirigentes para implementar a OQS, esses recursos podem ser visualizados equivocadamente como custos, e não como investimentos para melhorar a gestão cooperativa, principalmente no que tange às questões sociais.

\section{Referências}

ALCANTARA, L. C. S; SAMPAIO, C. A. C; ZABALA, L. U. Análise socioambiental: Zona de Educação para Ecodesenvolvimento e Experiência Cooperativa de Mondragón. Soc. estado, Brasília, v. 33, n. 3, p. 887-914, 2018. 
Artigos | A Organização do Quadro Social como instrumento da Educação Cooperativista (SOUSA, Diego Neves de; FERREIRA, Palloma Rosa)

ALCANTARA, L.C.S, SAMPAIO, C.A.C; URIARTE, L. Experiencia Cooperativa de Mondragón: la educación cooperativa como un proceso de transformación social. Revista de Economía Pública, Social y Cooperativa, v.93, 181-209, 2018.

FERREIRA, P. R; AMODEO, N. B. P; SOUSA, D. N. Os públicos atendidos e os conteúdos da educação cooperativista nas cooperativas agrárias. Revista Gestão e Desenvolvimento Regional, v. 9, n. 1, p. 67-90, 2013.

FERREIRA, P. R; SOUSA, D. N. Educação cooperativista: Aprofundando o conceito. Cooperativismo \& desarollo, v. 27, p. 1-32, 2019.

FERREIRA, P. R; SOUSA, D. N. O campo da educação cooperativista e sua relação com o Serviço Nacional de Aprendizagem do Cooperativismo (Sescoop). Interações, v. 19, p. 773, 2018.

FERREIRA, P. R; SOUSA, D. N; AMODEO, N. B. P. Situação da Educação Cooperativista nas Cooperativas Agropecuárias de Minas Gerais. Desenvolvimento em Questão, v. 16, p. 518$552,2018$.

FERREIRA, P. R; SOUSA, D. N; COSTA, M. S. Educación cooperativista y extensión rural. Revista Brasileira de Educação do Campo, v. 3, p. 411-432, 2018.

MACEDO, A. S; SOUSA, D. N.; AMODEO, N. B. P. A Organização do Quadro Social na interface entre gestão empresarial e social de cooperativas. Desenvolvimento em Questão, v. 12, p. 177-205, 2014.

MACEDO, A. S; SOUSA, D. N; AMODEO, N. B. P. O papel da comunicação na articulação dos diferentes níveis de organização no modelo central-singular de cooperativas. Bahia Analise \& Dados, v. 23, p. 89-105, 2013.

SOUSA, D. N; AMODEO, N. B. P; MACEDO, A. S; MILAGRES, C. S. F. As percepções sobre a articulação agroindustrial no modelo federado de cooperativas. Extensão Rural (Santa Maria), v. 22, p. 104-115, 2015.

SOUSA, D, N; AMODEO, N, B, P; MACEDO, A, S; MILAGRES, C, S, F. A comunicação na articulação agroindustrial entre uma cooperativa central, suas cooperativas singulares e cooperados. Revista de Economia e Sociologia Rural, v. 52, p. 495-514, 2014.

SOUSA, D. N; MACEDO, A. S; MILAGRES, C. S. F; COSTA, M. S; MOURA, R. A. A comunicação na gestão de cooperativas. Cadernos de Comunicação (UFSM), v. 22, p. 84-103, 2018.

SOUSA, D. N; PINHO, J. B; AMODEO, N. B. P; MILAGRES, C. S. F. A comunicação como ferramenta da educação cooperativista. Revista de Extensão e Estudos Rurais, v. 2, p. 57-78, 2013.

SUPERINTENDÊNCIA DE COOPERATIVISMO (SUDECOOP). O Papel do Técnico no Trabalho Educativo. Brasília, DF: SUDECOOP, 1994.

VALADARES, J. H. Profissionalização da gestão cooperativista: modismo ou necessidade? Revista Universo, ano 3, n. 16, p.66, 2005.

VALADARES, J. H. A Prática de Organização do Quadro Social nas Cooperativas Mineiras. Belo Horizonte, MG: OCEMG/PNFC/INTERCOOP. 1996.

VALADARES, J. H. Participação e poder: o Comitê Educativo na cooperativa agropecuária. 63 f. Dissertação (Mestrado em Administração Rural). Universidade Federal de Lavras, Lavras/MG, 1995. 